\title{
Usefulness of the Macruz Index for Predicting Successful Percutaneous Mitral Balloon Valvuloplasty in Patients with Mitral Stenosis
}

\author{
Kevser Gülcihan Balcı Mustafa Mücahit Balcı Orhan Maden Fatih Şen \\ Mehmet Kadri Akboga Burak Açar Meryem Kara Sadık Kadri Açıkgöz \\ Hatice Selcuk Mehmet Timur Selcuk \\ Department of Cardiology, Turkiye Yuksek Ihtisas Research and Education Hospital, Ankara, Turkey
}

\section{Key Words}

Percutaneous mitral balloon valvuloplasty · Macruz index ·

Mitral stenosis

\begin{abstract}
Objective: The aim of this study was to determine whether the Macruz index (P/P-R segment) could predict the severity of valvular involvement and the success of percutaneous mitral balloon valvuloplasty (PMBV) in patients with mitral stenosis (MS). Subjects and Methods: Sixty-one patients with MS eligible for PMBV and 72 healthy subjects ( 61 females and 11 males) with sinus rhythm were enrolled into this study. PMBV was performed in all patients using a percutaneous transseptal antegrade approach and a multitrack balloon technique. The P/P-R segment ratio and echocardiographic variables were measured before and $48-72 \mathrm{~h}$ after the procedure. The optimal cutoff point for differences in the Macruz index to determine clinical success was evaluated by receiver operating characteristic analysis by calculating the area under the curve as giving the maximum sum of sensitivity and specificity for the significant test. Results: In the patient group (mean age $42.9 \pm 11.1$ years), the preprocedural Macruz index was significantly higher than in the control group $(2.79 \pm 1.03$ vs. $1.29 \pm 0.11 ; p<0.001)$. In the success-
\end{abstract}

ful-procedure group $(n=53)$, the mean postindex value was significantly lower ( $2.12 \pm 0.71$ vs. $2.81 \pm 1.0, p=0.020)$, and the decrease in the Macruz index was significantly higher than in the unsuccessful-procedure group ( $p=0.007)$. An index decrease of 0.105 was the best cutoff value to distinguish the successful-PMBV group from the unsuccessfulPMBV group (area under the curve $=0.888,95 \%$ confidence interval 0.788-0.988, $p<0.001)$. Conclusion: The Macruz index was significantly higher in patients with MS compared to healthy subjects. A greater decrease in the Macruz index was associated with a successful PMBV.

(c) 2015 S. Karger AG, Basel

\section{Introduction}

The leading cause of mitral stenosis (MS) is rheumatic fever [1]. Rheumatic fever causes characteristic changes in the rheumatic mitral valve, i.e. thickened leaflet edges, fusion of the commissures and chordae tendineae, and chordal shortening [2]. The restricted valve orifice area leads to elevation of the left atrial (LA) pressure, and the resultant LA enlargement can precipitate atrial fibrillation (AF) [3]. P-wave dispersion (PWD), which is the difference between maximum and minimum P-wave dura-

\begin{tabular}{ll}
\hline KARGER & $\begin{array}{l}\text { () 2015 S. Karger AG, Basel } \\
1011-7571 / 15 / 0252-0110 \$ 39.50 / 0 \quad \text { Karger }\end{array}$ \\
$\begin{array}{l}\text { E-Mail karger@karger.com } \\
\text { www.karger.com/mpp }\end{array}$ & $\begin{array}{l}\text { This is an Open Access article licensed under the terms of the } \\
\text { Creative Commons Attribution-NonCommercial 3.0 Un- } \\
\text { ported license (CC BY-NC) (www.karger.com/OA-license), } \\
\text { applicable to the online version of the article only. Distribu- } \\
\text { tion permitted for non-commercial purposes only. }\end{array}$
\end{tabular}

Kevser Gülcihan Balc1, MD

Department of Cardiology, Turkiye Yuksek Ihtisas Research and Education Hospital Park Flora Sitesi B blok No:4, Yaşamkent Çayyolu

TR-06810 Altındağ, Ankara (Turkey)

E-Mail mbalc177@gmail.com 
tions and which is an electrocardiographic (ECG) AF marker, and MS have been reported to be related in previous studies [4-8]. Reduced PWD and maximum P-wave durations measured on day 1 and day 30 after percutaneous mitral balloon valvuloplasty (PMBV) have been reported [5]. Macruz et al. [9] used a formula based on the ratio of the P-wave duration to the P-R segment to determine right, left, and combined atrial enlargement and accepted values below 1.6 as normal. This simple formula, called the Macruz index, has been linked to LA abnormalities in numerous studies [10-13].

The presence of symptoms with severe to moderate MS and a favorable valve morphology in the absence of a LA thrombus or moderate-to-severe mitral regurgitation (MR) is an indication for PMBV [14]. A successful procedure may affect the ECG parameters in addition to relieving the symptoms [5]. The relationship between PWD, which is a marker for inhomogeneous and discontinuous propagation of sinus impulses $[15,16]$, and PMBV has been investigated $[4,5,7]$, but no data is available on the effects of PMBV on the Macruz index. Therefore, the aims of this study were to investigate the relationship between the Macruz index and the severity of MS and to determine whether this index could be helpful in predicting successful PMBV.

\section{Subjects and Methods}

\section{Patient Selection}

Two groups of patients were examined. Group 1 comprised patients who had moderate or severe MS ( 53 females and 8 males) with a favorable valve morphology and underwent PMBV at our institution from January 2002 to October 2013. Group 2 comprised the healthy control group (61 females and 11 males) without any known heart disease. All patients were in sinus rhythm. Exclusion criteria were: coronary artery disease, hypertension, diabetes mellitus, other significant valvular lesions, chronic obstructive pulmonary disease, and current treatment with antiarrhythmic drugs. The indications for PMBV were: symptoms with moderate or severe MS with a favorable valve morphology, or no symptoms with moderate to severe MS and pulmonary hypertension (pulmonary artery systolic pressure $>50 \mathrm{~mm} \mathrm{Hg}$ at rest) with a favorable valve morphology. The study protocol was approved by the Institutional Ethics Committee.

\section{Electrocardiogram}

A 12-lead electrocardiogram was recorded at a paper speed of $25 \mathrm{~mm} / \mathrm{s}$, a sensitivity of $1 \mathrm{mV} / \mathrm{cm}$, and filter settings of $0.05-40$ $\mathrm{Hz}$ for each patient before and 48-72 h after the PMBV calipers and magnifying lens had been used to avoid inaccurate measurements. P-wave duration was measured from its earliest departure from baseline to the end of the $\mathrm{P}$-wave, and the P-R segment was measured from termination of the $\mathrm{P}$ wave to the beginning of the first deflection attributable to the ventricular complex. P-wave and $\mathrm{P}-\mathrm{R}$ segment durations were determined by averaging 5 consecutive beats from the rhythm strip record [17]. The Macruz index was defined as the P/P-R segment ratio [9].

\section{Echocardiographic Evaluation}

All of the patients underwent comprehensive 2-dimensional (2D) and color Doppler transthoracic echocardiography (Vivid 7 Ultrasound System; GE, Horten, Norway) before and after PMBV. Measurements were obtained at rest in the left lateral decubitus position. Wilkins' echo scoring system [18] was used to calculate the valvular score according to leaflet mobility, thickness, calcification, and subvalvular lesions. The LA diameter was measured by M-mode echocardiography, and the planimetric method or the pressure half-time method (in the absence of significant MR) was used to calculate the mitral valve area (MVA). Mean transmitral diastolic mitral valve gradients (mMVG) were calculated using a Doppler ultrasound scanning assessment. MR was evaluated with color flow Doppler. Continuous-wave Doppler was used to calculate the peak pressure gradient of the tricuspid regurgitation jet velocity, and the systolic pulmonary artery pressure was calculated by adding the right atrial pressure $(10 \mathrm{~mm} \mathrm{Hg})$ to this value. All patients were screened for LA thrombus with a $2 \mathrm{D}$ transesophageal echocardiogram less than $24 \mathrm{~h}$ prior to the procedure.

\section{Percutaneous Mitral Balloon Valvuloplasty}

After $12 \mathrm{~h}$ of fasting and under local anesthesia and mild sedation (diazepam $2.5-5 \mathrm{mg}$ ), all eligible patients $(\mathrm{n}=61)$ underwent PMBV via a percutaneous transseptal antegrade approach and a multitrack balloon technique. The pressure on the right and left sides of the heart was evaluated before and after the procedure. The procedure was terminated if a satisfactory result (MVA $>1.5 \mathrm{~cm}^{2}$ or valve area increment $\geq 50 \%$ without $>2+\mathrm{MR}$ ) was achieved.

\section{Statistical Analysis}

Data analysis was performed using SPSS for Windows, version 11.5 (SPSS Inc., Chicago, Ill., USA). The normality of the distributions of continuous variables was determined using the Kolmogorov-Smirnov test. Continuous variables were reported as means \pm SD or medians (range), where applicable.

Differences in mean values between groups were compared using Student's t test. Nominal data were analyzed by Pearson's $\chi^{2}$ test. Whether the statistically significant difference in the mean mitral index between the case and control groups was to be continued or not was evaluated by analysis of covariance after adjustment for age. The mean differences between pre- and postPMBV measurements were compared using a paired t test; otherwise, the Wilcoxon signed-ranked test was applied for comparison of median values. The degree of association between continuous variables was evaluated by Spearman's rank correlation analyses.

The optimal cutoff point for differences in the Macruz index to determine clinical success was evaluated by receiver operating characteristic (ROC) analysis by calculating the area under the curve as giving the maximum sum of sensitivity and specificity for the significant test. Sensitivity, specificity, positive and negative predictive values, and accuracy rates were also calculated at the best cutoff point for differences in the mitral index. $\mathrm{p}<0.05$ was considered statistically significant. 
Table 1. Baseline clinical characteristics of the patients with MS and the control group

\begin{tabular}{lccr}
\hline Variables & $\begin{array}{l}\text { Patient group } \\
(\mathrm{n}=61)\end{array}$ & $\begin{array}{l}\text { Control group } \\
(\mathrm{n}=72)\end{array}$ & p values \\
\hline Age, years & $42.9 \pm 11.1$ & $40.4 \pm 8.6$ & 0.704 \\
Male & $8(13.1 \%)$ & $11(15.3 \%)$ & 0.830 \\
Female & $53(86.9 \%)$ & $61(84.7 \%)$ & 0.410 \\
Body surface area, $\mathrm{m}^{2}$ & $1.75 \pm 0.16$ & $1.74 \pm 0.22$ & 0.502 \\
Systolic blood pressure, $\mathrm{mm} \mathrm{Hg}$ & $98.5 \pm 10.0$ & $100 \pm 9.7$ & 0.230 \\
Diastolic blood pressure, $\mathrm{mm} \mathrm{Hg}$ & $62.1 \pm 6.8$ & $60 \pm 7.9$ & 0.608 \\
Heart rate, beats/min & $79 \pm 7$ & $79 \pm 5$ & $<0.001$ \\
LA diameter, cm & $4.54 \pm 4.21$ & $3.6 \pm 0.17$ & 0.740 \\
Left ventricular ejection fraction, $\%$ & $64 \pm 3$ & $65 \pm 3$ & $<0.001$ \\
Macruz index & $2.79 \pm 1.03$ & $1.29 \pm 0.11$ & \\
\hline
\end{tabular}

Table 2. Macruz index measurements before and after PMBV

\begin{tabular}{llcr}
\hline Variables & Pre-PMBV & Post-PMBV & p value \\
\hline Macruz index & $2.79 \pm 1.03$ & $2.23 \pm 0.79$ & $<0.001$ \\
MVA, cm ${ }^{2}$ & $1.15(0.80-1.50)$ & $1.70(1.00-2.50)$ & $<0.001$ \\
LA diameter, cm & $4.60(3.90-5.70)$ & $4.30(4.00-5.70)$ & 0.182 \\
Pulmonary artery pressure, mm Hg & $45(27-90)$ & $36(24-75)$ & $<0.001$ \\
mMVG, mm Hg & $11(5-25)$ & $5(2-12)$ & $<0.001$ \\
\hline
\end{tabular}

Values are presented as means \pm SD or medians (range) unless otherwise stated.

\section{Results}

There were no significant differences between patients and controls in terms of the mean age (42.9 \pm 11.1 vs. $40.4 \pm 8.6$ years, $\mathrm{p}=0.704)$, body surface area $(1.75 \pm$ 0.16 vs. $1.74 \pm 0.22, \mathrm{p}=0.410)$, blood pressure $(98.5 \pm$ 10.0 vs. $100 \pm 9.7, \mathrm{p}=0.502)$, or left ventricular ejection fraction ( $64 \pm 3$ vs. $65 \pm 3, p=0.740)$. The mean LA diameter was significantly higher in the patient group compared to the control group $(4.54 \pm 4.21$ vs. $3.6 \pm 0.17 \mathrm{~cm}$, $\mathrm{p}<0.001)$. The preprocedural mean Macruz index value was significantly higher in the patient group compared to the control group $(2.79 \pm 1.03$ vs. $1.29 \pm 0.11, \mathrm{p}<0.001$; table 1).

Among patients who underwent PMBV $(\mathrm{n}=61), 53$ (86.9\%) experienced a successful PMBV. In the unsuccessful-PMBV group $(\mathrm{n}=8 ; 13.1 \%), \mathrm{MR}>2^{\circ}$ occurred in 3 patients, the MVA remained $<1.5 \mathrm{~cm}^{2}$ in 3 patients, and the MVA increment in 2 patients was $<50 \%$. The median valvular score was $8(5-10)$ in all patients. In the unsuccessful-procedure group, 5 patients had a valvular score $>8$, and 3 patients had a score $\leq 8$.
The median postprocedural MVA was significantly higher than the preprocedural MVA (1.70 vs. $1.15 \mathrm{~cm}^{2}$, $\mathrm{p}<0.001)$. The median postprocedural systolic pulmonary arterial pressure ( 36 vs. $45 \mathrm{~mm} \mathrm{Hg}$ ) and mMVG (5 vs. $11 \mathrm{~mm} \mathrm{Hg}$ ) were significantly lower than the preprocedural values $(\mathrm{p}<0.001)$. The mean postprocedural Macruz index values were significantly lower than the preprocedural values $(2.23 \pm 0.79$ vs. $2.79 \pm 1.03, \mathrm{p}<0.001$; fig. 1). There was no significant difference in terms of the median pre-LA and post-LA diameters ( 4.6 vs. $4.3 \mathrm{~cm}$, $\mathrm{p}=0.182$; table 2).

There was no significant correlation between preMVA and preindex values $(r=0.045)$, post-MVA and postindex values $(r=-0.127)$, or change in MVA and change in index values $(r=-0.172 ; p>0.05)$. There was also no significant correlation between pre-LA and preindex values, post-LA and postindex values, or change in LA diameter and change in index values $(\mathrm{p}>0.05)$. There was no significant correlation between valvular scores and preindex values, valvular scores and postindex values, or valvular scores and change in index values ( $\mathrm{p}>$ 0.05 ; table 3 ). 
Table 3. Correlations between change in the Macruz index and valvular score, LA diameter, and MVA before and after PMBV

\begin{tabular}{lrrr}
\hline Variables & Pre-PMBV & Post-PMBV & Difference \\
\hline MVA & & & \\
$\quad$ Correlation coefficient & 0.045 & -0.127 & -0.172 \\
$\quad$ p value & 0.732 & 0.331 & 0.185 \\
LA diameter & & & \\
$\quad$ Correlation coefficient & -0.179 & -0.746 & 0.580 \\
$\quad$ p value & 0.734 & 0.088 & 0.228 \\
Valvular score & & & \\
$\quad$ Correlation coefficient & -0.131 & -0.012 & 0.120 \\
$\quad$ p value & 0.315 & 0.927 & 0.356 \\
\hline
\end{tabular}

There was no significant difference in terms of preindex values in either the successful- or the unsuccessfulPMBV group ( $\mathrm{p}=0.873)$. However, in the successful-procedure group the mean postindex values were significantly lower $(\mathrm{p}=0.020)$, and the decrease in postindex values compared to preindex values was significantly higher than in the unsuccessful-procedure group $(\mathrm{p}=0.007$; table 4).

The area under the ROC curve was statistically significant for distinguishing the successful-PMBV group from the unsuccessful-PMBV group based on the change in postindex values compared to preindex values (area under the curve $=0.888,95 \%$ CI $0.788-0.988, \mathrm{p}<0.001$; fig. 2). The best cutoff point of the ROC curve to distinguish the successful-PMBV group from the unsuccessfulPMBV group with changes in postindex values compared to preindex values was -0.105 , with a sensitivity of $88.5 \%$, a specificity of $87.5 \%$, and positive and negative predictive values of 97.9 and $53.8 \%$ (table 5).

\section{Discussion}

In this study, the Macruz index was significantly higher in the patient group compared to the control group, but there was no significant correlation between valvular scores, the severity of valvular involvement, and the Macruz index in the patient group. After PMBV, the Macruz index decreased significantly, and the decrement was more pronounced in the successful-procedure group.

In our study, an increased LA pressure and LA diameter in patients with MS resulted in a higher Macruz index [19] compared to healthy subjects with a normal LA di-

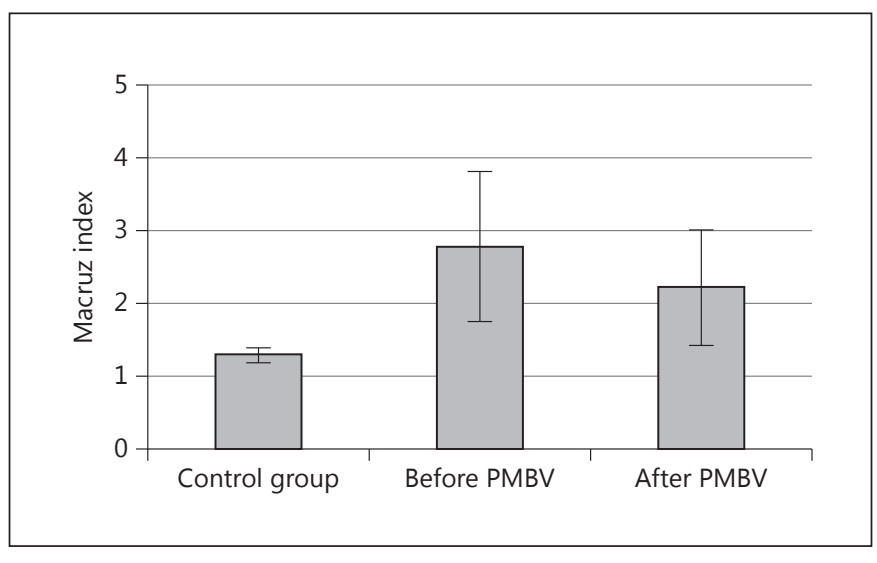

Fig. 1. Comparison of the Macruz index between study groups.

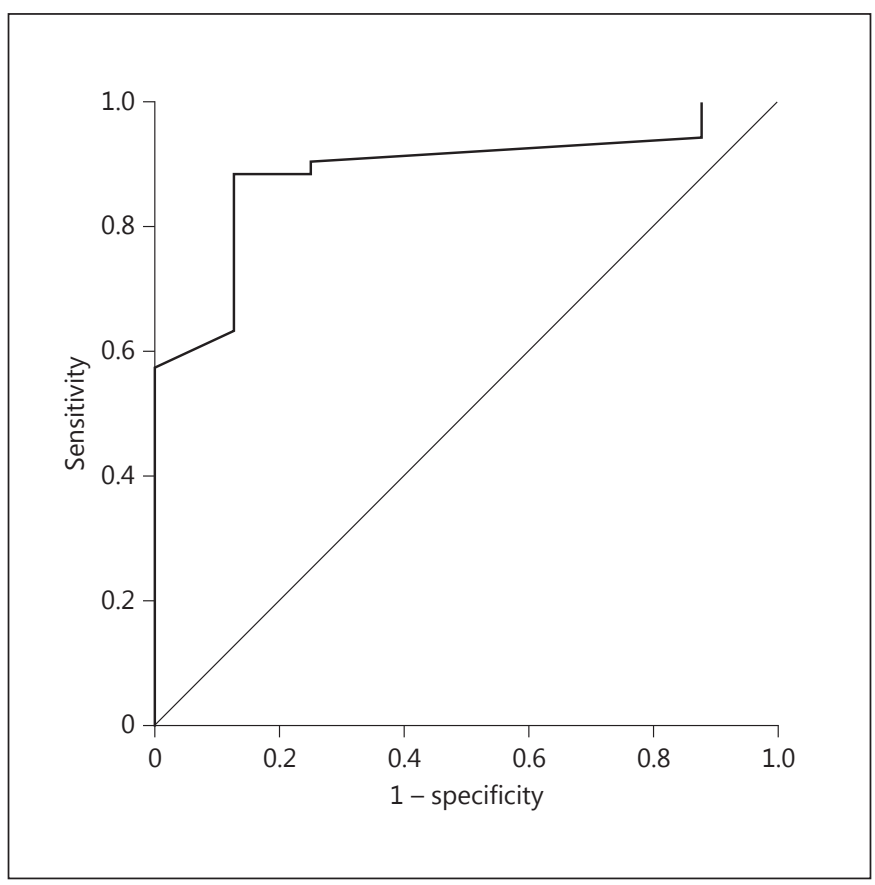

Fig. 2. ROC curve for the change in Macruz index for predicting clinical success.

ameter. Previously, the Macruz index has been shown to be a more helpful ECG index of atrial function abnormality rather than anatomic abnormality in different diastolic dysfunction patient subsets $[10,20]$. Moreover, it has been claimed that the Macruz index should be useful for diagnosis of MS [21]. MS is a mechanical cause of diastolic dysfunction leading to increased resistance to diastolic ventricular filling; therefore, in our study, the de- 
Table 4. Change in the Macruz index before and after PMBV according to clinical success

\begin{tabular}{lccc}
\hline Macruz index & $\begin{array}{l}\text { Unsuccessful-procedure } \\
\text { group }(\mathrm{n}=8)\end{array}$ & $\begin{array}{l}\text { Successful-procedure } \\
\text { group }(\mathrm{n}=53)\end{array}$ & p value \\
\hline Pre-PMBV & $2.83 \pm 0.92$ & $2.76 \pm 1.05$ & 0.873 \\
Post-PMBV & $2.81 \pm 1.00$ & $2.12 \pm 0.72$ & 0.020 \\
Change in the Macruz index & $-0.02 \pm 0.20$ & $-0.64 \pm 0.63$ & 0.007 \\
\hline
\end{tabular}

Table 5. ROC analysis indicating the best cutoff value for the change in Macruz index that predicts clinical outcomes and diagnostic performance measures $(n=61)$

\begin{tabular}{lccc}
\hline Statistic & $\begin{array}{l}\text { Mitral index } \\
\text { difference }\end{array}$ & Definition & n/total (\%) \\
\hline AUC & 0.888 & & \\
95\% CI for the AUC & $0.788-0.988$ & & \\
p value & $<0.001$ & & \\
Best cutoff point & $<-0.105$ & $\mathrm{TP} /(\mathrm{TP}+\mathrm{FN})$ & $76 / 52(88.5)$ \\
Sensitivity & & $\mathrm{TN} /(\mathrm{TN}+\mathrm{FP})$ & $7 / 8(87.5)$ \\
Specificity & & $\mathrm{TP} /(\mathrm{TP}+\mathrm{FP})$ & $76 / 47(97.9)$ \\
PPV & & $\mathrm{TN} /(\mathrm{TN}+\mathrm{FN})$ & $7 / 13(53.8)$ \\
NPV & & $(\mathrm{TP}+\mathrm{TN}) /(\mathrm{TP}+\mathrm{TN}+\mathrm{FP}+\mathrm{FN})$ & $53 / 61(88.3)$ \\
Accuracy & & &
\end{tabular}

$\mathrm{AUC}=$ Area under the curve; $\mathrm{TP}=$ true positive; $\mathrm{FN}=$ false negative; $\mathrm{TN}=$ true negative; $\mathrm{FP}=$ false positive; $\mathrm{PPV}=$ positive predictive value; NPV = negative predictive value.

crease in the Macruz index might suggest an acute fall in LA pressure after successful MBVP.

In this study, there was no significant correlation between preindex and pre-MVA or pre-LA diameters, or between postindex and post-MVA or post-LA diameters. Equally, there was no significant correlation between index change and improvement in MVA or LA diameter. The lack of a significant correlation in these values could be due to remarkable electrical and structural changes that could occur in the months following the procedure. Our results confirmed the findings of the study of Turhan et al. [4] and Kazemi et al. [5], who reported no significant correlation between PWD and echocardiographic parameters in patients with MS who underwent PMBV [4, 5]. Our findings support the view that the disease process is more complicated than can be explained by simple ECG and echocardiographic parameters, and these results could differ in each patient depending on the discrepant characteristics of the disease and the patients.
The most striking finding of the present study is that the difference between preindex and postindex values was useful in distinguishing between the successful- and unsuccessful-procedure groups in this cohort. Although there was no significant difference in preindex values between the successful- and unsuccessful-procedure groups, the mean postindex values were significantly lower in the successful-procedure group compared to the unsuccessful-procedure group.

Numerous studies have investigated the effect of an acute reduction of atrial stretch after PMBV on both ECG $[4,5,22-24]$ and echocardiographic $[7,25]$ parameters. Demirkan et al. [7] found decreased PWD and improved left-sided intra-atrial electromechanical delay after successful PMBV, and they suggested that successful PMBV reduces the susceptibility to AF even in the early period. Kazemi et al. [5] demonstrated a decrease in Pmax and PWD only after a successful procedure [5]. In our study, although we did not observe a significant correlation between LA diameter and the Macruz index, the Macruz 
index may be more representative of LA functional changes rather than anatomical changes. We observed a more pronounced reduction in Macruz index when the procedure was successful, suggesting that a reduction in Macruz index after PMBV might have indicated a reduction in LA pressure. In addition to decreased LA pressure, decreased systolic pulmonary artery pressure can affect the P-wave indices [26]; therefore, the decreased pulmonary pressure might have contributed to the ECG changes. An effective procedure causes delay or even prevention of the initiation of AF by inhibiting electrical and structural remodeling of the atria [5, 27]. Patients with rheumatic MS and AF have a worse overall prognosis compared to the general population [2] and they are strongly advised to receive oral anticoagulation treatment regardless of their $\mathrm{CHA}_{2} \mathrm{DS}_{2}$-VASc score (congestive heart failure, hypertension, age, diabetes mellitus, stroke, vascular disease, and female gender) because of their higher embolic risk profile related to LA structural changes [28]. Hence, embolic complications in MS are a major cause of morbidity and mortality; early detection of patients who could benefit from oral anticoagulation treatment for stroke prevention is crucial. Compared to healthy subjects, patients with MS had a greater Macruz index. This index may be useful, like PWD, for demonstrating inhomogeneous and discontinuous propagation of sinus impulses, and it may provide clues to the arrhythmic tendency of the atria in patients with MS. PMBV, when successful, may reduce the arrhythmic tendency of the atrial wall by reducing the stretch on it.

The most important limitations of this study were its retrospective design and small sample size. In addition, the Macruz index is not applicable to patients with AF. Another limitation was the absence of follow-up data for these patients, and hence we have no information on whether patients with a higher Macruz index and/or a less decreased index experienced AF or not. Further studies with a prospective design are needed to investigate the AF incidence in patients with MS and a higher Macruz index.

\section{Conclusion}

In this study, the Macruz index was higher in patients with MS than in healthy subjects. This index decreased after the PMBV procedure probably due to the diminished LA pressure. The greater decrease in the Macruz index after PMBV was associated with a successful PMBV.

\section{References}

1 Lung B, Baron G, Butchart EG, et al: A prospective survey of patients with valvular heart disease in Europe: the Euro Heart Survey on valvular heart disease. Eur Heart J 2003;24: 1231-1243.

2 Robert OB, Otto CM: Braunwald's Heart Disease: A Text Book of Cardiovascular Medicine, ed 9. Philadelphia, Elsevier Saunders, 2012, pp 1490-1499.

3 Ray R, Chambers J: Mitral valve disease review article. Int J Clin Pract 2014;68:12161220.

4 Turhan H, Yetkin E, Senen K, et al: Effects of percutaneous mitral balloon valvuloplasty on $\mathrm{P}$-wave dispersion in patients with mitral stenosis. Am J Cardiol 2002;89:607-609.

5 Kazemi B, Rostami A, Aslanabadi N, et al: Electrocardiographic P-wave Indices as a useful tool to predict successful percutaneous balloon mitral valvotomy in patients with mitral stenosis. J Cardiovasc Thorac Res 2014;6: 9-14.

6 John B, Stiles MK, Kuklik P, et al: Electrical remodelling of the left and right atria due to rheumatic mitral stenosis. Eur Heart J 2008; 29:2234-2243.

7 Demirkan B, Guray Y, Guray U, et al: The acute effect of percutaneous mitral balloon valvuloplasty on atrial electromechanical de lay and $\mathrm{P}$-wave dispersion in patients with $\mathrm{mi}$ tral stenosis. Herz 2013;38:210-215.

8 Guntekin U, Gunes Y, Tuncer M, et al: Long-term follow-up of P-wave duration and dispersion in patients with mitral stenosis. Pacing Clin Electrophysiol 2008;31: 1620-1624.

-9 Macruz R, Perloff JK, Case RB: A method for the electrocardiographic recognition of atrial enlargement. Circulation 1958; 17:882.

10 Genovesi-Ebert A, Marabotti C, Palombo C, et al: Electrocardiographic signs of atrial overload in hypertensive patients: indexes of abnormality of atrial morphology or function? Am Heart J 1991;121:1113-1118.

11 Wagner G, Syska J, Kienast W, et al: Significance of the Macruz index in the diagnosis of atrial enlargement in infancy (in German). Kinderarztl Prax 1976;44:541-544.

12 Vijayalaxmi B, Sanyal SK, Thapar MK, et al: Evaluation of Macruz index in assessment left atrial enlargement in childhood. Indian Heart J 1972;24:109-114.

13 Milillo V, Cantarini G: On the validity of the $\mathrm{P}$ wave-PQ segment or Macruz index in the electrocardiographic diagnosis of atrial enlargement. Cardiol Prat 1968;19:393-400.
14 Nishimura RA, Otto CM, Bonow RO, et al 2014 AHA/ACC guideline for the management of patients with valvular heart disease: a report of the American College of Cardiology/American Heart Association Task Force on Practice Guidelines. J Am Coll Cardiol 2014;63:e57-e185.

15 Dilaveris PE, Gialafos EJ, Andrikopoulos GK, et al: Clinical and electrocardiographic predictors of recurrent atrial fibrillation. Pacing Clin Electrophysiol 2000;23:352-358.

16 Dilaveris PE, Gialafos EJ, Sideris S, et al: Simple electrocardiographic markers for the prediction of paroxysmal idiopathic atrial fibrillation. Am Heart J 1998;135:733-738.

17 Harikrishnan S, Bohora S, Pillai VV, et al: Left atrial myxoma-influence of tumour size on electrocardiographic findings. Indian Heart J 2012;64:170-172.

$>18$ Wilkins GT, Weyman AE, Abascal WM, et al: Percutaneous balloon dilatation of the mitral valve: an analysis of echocardiographic variables related to outcome and the mechanism of dilatation. Br Heart J 1988;60: 299-308.

19 Human GP, Snyman HW: The value of the Macruz index in the diagnosis of atrial enlargement. Circulation 1963;27:935-938. 
20 Xia XF, Zhang FR: Changes in Macruz index of patients with coronary artery diseases and their clinical implications (in Chinese). Di Yi Jun Yi Da Xue Xue Bao 2003;23:862-863.

21 Wierzchowska D, Czaplicki S: Usefulness of the Macruz index in the diagnosis of mitral stenosis (in Polish). Kardiol Pol 1965;8:43-45.

22 Soylu M, Demir AD, Ozdemir O, et al: Evaluation of atrial refractoriness immediately after percutaneous mitral balloon commissurotomy in patients with mitral stenosis and sinus rhythm. Am Heart J 2004;147:741-745.

23 Chandrasekar B, Loya YS, Sharma S, et al: Acute effect of balloon mitral valvotomy on serial electrocardiographic changes and their haemodynamic correlation. Indian Heart J 1998;50:179-182.
24 Coronel R, Langerveld J, Boersma LV, et al: Left atrial pressure reduction for mitral stenosis reverses left atrial direction-dependent conduction abnormalities. Cardiovasc Res 2010;85:711-718.

25 Mahfouz RA, Elawady W, Hossein E, et al: Impact of atrioventricular compliance on clinical outcome of patients undergoing successful percutaneous balloon mitral valvuloplasty. Echocardiography 2013;30:11871193.

26 Mahfouz RA, Dewedar AE: The prognostic impact of $\mathrm{P}$ wave dispersion in prediction of clinical outcome after percutaneous balloon mitral valvuloplasty in patients with mitral stenosis and sinus rhythm. World J Cardiovasc $D$ is 2013;3:82-89.
7 Fawzy ME, Shoukri M, Al Sergani H, et al: Favorable effect of balloon mitral valvuloplasty on the incidence of atrial fibrillation in patients with severe mitral stenosis. Catheter Cardiovasc Interv 2006;68:536-541.

28 Hughes M, Lip GY; Guideline Development Group, National Clinical Guideline for Management of Atrial Fibrillation in Primary and Secondary Care, National Institute for Health and Clinical Excellence: Stroke and thromboembolism in atrial fibrillation: a systematic review of stroke risk factors, risk stratification schema and cost effectiveness data. Thromb Haemost 2008;99:295-304. 